Family Medicine and Community Health

\section{Chronic pain care: time for excellence}

To cite: Heath L, Philip A. Chronic pain care: time for excellence. Fam Med Com Health 2020;8:e000285. doi:10.1136/fmch-2019-000285

\section{ABSTRACT}

The current health system aims to cope with the epidemic of chronic pain. The narrative urgently needs to be reset to one that strives for excellence. This reflection illustrates what excellence may look like and also highlights where system biases are preventing positive change from occurring.

Chronic pain is more prevalent in the US population than diabetes, heart disease and cancer combined. It disproportionately affects the elderly, the economically disadvantaged and women. ${ }^{1}$ Globally, chronic pain, including lower back pain, neck pain and headache, are among the leading causes of years lived with disability. ${ }^{2}$ Yet primary care practices and providers often lack the support and training to address the magnitude of this problem, fuelling an overreliance on medication monotherapy, including opioids. Better integration of effective behavioural pain management principles and practices within primary care is one key method for addressing this epidemic of pain.

The problem starts early in training. Medical students are exposed to negative attitudes towards people with chronic pain. ${ }^{3}$ Time spent on chronic pain is low, with $80 \%$ of North American medical schools having no formal chronic pain curriculum. ${ }^{4}$ Despite this, there are examples of undergraduate medical curricula embracing efforts to teach an integrated model of chronic pain management, resulting in empowered medical students with confidence to provide future excellent care. ${ }^{5}$

The logic is easy to follow. If a patient presents in pain, prescribe a painkiller. But this does not treat the multifaceted, nuanced nature of chronic pain, and with prolonged use, increases the likelihood of disability and other correlates of poorly managed pain. ${ }^{6}$ Of the individuals who misuse pain relievers, up to six out of ten do so to relieve pain. ${ }^{7}$ Treatment options for chronic pain need urgent improvement. Something must change.

We know what works: Access to a full range of behavioural, social and physical health services in a patient-centred context, overseen by a consistent primary care provider
(PCP). ${ }^{8}$ There are many examples of integration success, and these have taken a variety of bidirectional forms. The important underlying principle is the linkage of programmes, activities and professionals to promote holistic, patient-centred care. An appreciation of the need for integration is the first step, followed by co-operation, collaboration and then full partnership. Co-location of a behavioural health professional is the beginning, but full integration requires them to be part of primary care team huddles, the practice of warm hand-offs and to fully participate in the patient journey. Simple steps like equitable sharing of clinical space and involvement in the social fabric of a practice can help set the right trajectory for team collaboration. Clinicians report greater levels of care satisfaction and patients record greater quality-of-life scores with these innovative arrangements. ${ }^{10}$ By seeking regular feedback on these real-world components of integration, practices can bypass common struggles in fully integrating staff.

PCP support is crucial in an integration process as providers can advocate for and act as the gatekeepers to appropriate behavioural health services. Cognitive-behavioural therapy (CBT) is a gold-standard intervention for chronic pain, yet is frequently seen as an add-on to medication approaches, and therefore underused as an important treatment in primary care settings. ${ }^{11}$ CBT can be incorporated into more accessible formats in exciting new ways, from online versions to single intensive sessions, to numerous apps, videos and websites for improving selfmanagement. Recent trials have shown more flexible, app-based CBT options to be acceptable alternatives. ${ }^{13}$ Discussion with patients about the modality that best suits their lifestyle is likely to improve their compliance and acceptance with this important component of treatment.

But patients deserve even more than this. All too often, evidence-based behavioural health interventions are held to 'double standards' when compared with medical or surgical equivalents. We talk about cost savings and potential reductions in absences at work 
when discussing behavioural intervention efficacy. While such benefits may at times hold true, the discussion illustrates a deeply held, systemic level bias-that behavioural interventions must reach a higher level of effectiveness in order to be justifiable. Never would this apply to medical specialties; cost saving in novel oncology or heart disease interventions is unheard of. In comparison, pain and behavioural interventions are poorly understood and even more poorly valued.

This systemic bias is partly due to the stigma of chronic pain and opioid addiction. Providers need to recognise that patients may be reluctant to disclose symptoms if they feel they may be dismissed or suspected of exaggeration. Countering these presumptions requires a shift of consultation approach: affirm symptoms disclosed, reassure that many other patients suffer from similar symptoms and emphasise the evidence-based treatments that cover biological, psychological and social aspects of pain. Just as appropriate imaging and labs should be requested, an explanation of central sensitisation as the likely pathological mechanism for chronic pain must also be provided. The larger message is that these symptoms are valid, have a cause and can be addressed through a variety of effective treatments.

Providers and practices should aspire for a proactive, rather than reactive, approach. If a patient in pain is approaching the 3-month point (the somewhat arbitrary but defining point when pain is classified as chronic), providers should think proactively, identifying whether this patient is at risk. In the same way there is a 'bundle' of services patients with other conditions have access to at the point of diagnosis, this should be the case with chronic pain. At diagnosis, patients could be directed on a supported but structured 'pain pathway' where referrals to all key health professionals are made automatically. Review appointments with the PCP scheduled, so progress can be tracked and additional referrals made as appropriate. This way, accessing services is not based on ability to self-advocate but rather on the presence of a diagnosis and clinical need. Such practices would promote health equity and help ensure the most vulnerable get access the care they need.

Providing appropriate, holistic care to this patient group can seem daunting. Attempting to address the biological process and social needs and psychological components of chronic pain may appear to consume time and invite issues, such as social needs, that providers may feel they are unable to address. Yet, this is precisely why integration is required. The nature of chronic pain means that treatment involves these components and that healthcare professionals operating in silos cannot deliver best-quality, evidence-based care. Treatment of chronic pain needs to be publicly re-framed as a condition, like any other, that deserves proactive, evidence-based treatment. Healthcare delivery should be restructured to ensure that healthcare needs of the most vulnerable are met. This is a call to action for practices and providers to strive for excellence, not simply survival, in care for this patient population.

\section{Twitter Laura Heath @laurahheath and Andrew Philip @APhilipPsych}

Contributors LHH and AP conceived the idea. LHH wrote the manuscript with support at all stages from AP.

Funding LHH received assistance from The Margaret E. Mahoney Fellowship Program of The New York Academy of Medicine.

Competing interests None declared.

Patient consent for publication Not required.

Provenance and peer review Not commissioned; externally peer reviewed.

Open access This is an open access article distributed in accordance with the Creative Commons Attribution Non Commercial (CC BY-NC 4.0) license, which permits others to distribute, remix, adapt, build upon this work non-commercially, and license their derivative works on different terms, provided the original work is properly cited, appropriate credit is given, any changes made indicated, and the use is non-commercial. See: http://creativecommons.org/licenses/by-nc/4.0/.

ORCID iD

Laura Heath http://orcid.org/0000-0002-1628-1981

\section{REFERENCES}

1 Dahlhamer J, Lucas J, Zelaya C, et al. Prevalence of chronic pain and high-impact chronic pain among adults-United States, 2016. MMWR Morb Mortal Wkly Rep 2018;67:1001-6.

2 GBD 2016 Disease and Injury Incidence and Prevalence Collaborators. Global, regional, and national incidence, prevalence, and years lived with disability for 328 diseases and injuries for 195 countries, 1990-2016: a systematic analysis for the global burden of disease study 2016. Lancet 2017;390:1211-59.

3 Loeser JD, Schatman ME. Chronic pain management in medical education: a disastrous omission. Postgrad Med 2017;129:332-5.

4 Mezei L, Murinson BB, Johns Hopkins Pain Curriculum Development Team. Pain education in North American medical schools. J Pain 2011;12:1199-208.

5 Vargovich AM, Schumann ME, Xiang J, et al. Difficult conversations: training medical students to assess, educate, and treat the patient with chronic pain. Acad Psychiatry 2019;43:494-8.

6 Ashworth J, Green DJ, Dunn KM, et al. Opioid use among low back pain patients in primary care: is opioid prescription associated with disability at 6-month follow-up? Pain 2013;154:1038-44.

7 Voon P, Karamouzian M, Kerr T. Chronic pain and opioid misuse: a review of reviews. Subst Abuse Treat Prev Policy 2017;12:36.

8 Kamper SJ, Apeldoorn AT, Chiarotto A, et al. Multidisciplinary biopsychosocial rehabilitation for chronic low back pain: cochrane systematic review and meta-analysis. BMJ 2015;350:h444.

9 Mills S, Torrance N, Smith BH. Identification and management of chronic pain in primary care: a review. Curr Psychiatry Rep 2016;18:22.

10 Elrashidi MY, Mohammed K, Bora PR, et al. Co-located specialty care within primary care practice settings: a systematic review and meta-analysis. Healthc 2018;6:52-66.

11 Ehde DM, Dillworth TM, Turner JA. Cognitive-behavioral therapy for individuals with chronic pain: efficacy, innovations, and directions for research. Am Psychol 2014;69:153-66.

12 Schneiderhan J, Clauw D, Schwenk TL. Primary care of patients with chronic pain. JAMA 2017;317:2367-8.

13 Hauser-Ulrich S, Künzli H, Meier-Peterhans D, et al. A smartphonebased health care Chatbot to promote self-management of chronic pain (SELMA): pilot randomized controlled trial. JMIR Mhealth Uhealth 2020;8:e15806. 